\title{
Effect of damper positions in reducing vibration for internal turning process
}

\begin{abstract}
Vibration is known as one of the resources of roughness in machining. Many studies attempt to find how to reduce vibration during machining. This research investigated surface roughness in internal turning process (boring). Overhang is a major problem during boring process, the longer the object, the more vibrations would be generated. It may cause tool deflect causing an effect on the tool life, surface finish and dimensional accuracy. Four parameters were examined i.e. Damper position; Feed rate; Depth of cut; and Insert radius. The unique of this research is to find position of damper in the tool holder to reduce the vibration. Full factorial of design of experiment applied. Analysis of variance was used to identify the significant contribution of each variable. Based on the results, Feed rate and Insert radius have significant influence on roughness. Among the combinations of two factors and higher interactions, the results show that two factor interactions, damper positioninsert radius and depth of cut-insert radius significantly influenced surface roughness. For three factor interaction, none were significant. However, the four factor interaction i.e. damper position-feed rate-depth of cut-insert radius influenced the roughness significantly. The study revealed that location of the damper indeed has an effect on the roughness. The suitable position of damper was put on the top of the tool bar parallel to y-axis.
\end{abstract}

Keywords: damper position, depth of cut, feed rate, insert radius, internal turning
Volume 4 Issue I - 2020

\author{
Adi Saptari, Wasis Nugroho, Mohd Nizam \\ Abdul Rahman, Effendi Mohamad, Mohd Rizal \\ Salleh,T Joseph Sahaya Anand \\ Faculty of Manufacturing Engineering, Universiti Teknikal \\ Malaysia Melaka, Malaysia
}

Correspondence: $T$ Joseph Sahaya Anand, Faculty of Manufacturing Engineering, Universiti Teknikal Malaysia Melaka, Durian Tunggal, 76100 Melaka, Malaysia, Tel +60-6-33I 6489, Fax +60-6-33I 64II, Email anand@ute.edu.my

Received: December 24, 2019 | Published: April 20, 2020

\section{Introduction}

The mechanism of formation of surface roughness is complicated and process dependent. To select the optimum cutting parameters properly, several mathematical models based on statistical regression or neural network techniques have been constructed to establish the relationship between the cutting performance and cutting parameters. ${ }^{1,2}$ The methods widely used to select the correct setting of parameters are Design of Experiment (DoE) and Taguchi method. It provides an efficient and systematic approach to optimize design parameters for performance and quality. ${ }^{3}$ The method is valuable when the design parameters applied to reduce the sensitivity of the system performance to sources of variation. The parameters may form a mathematic formulation of an objective function and the constrains. To find the optimal cutting parameters some optimization techniques are used. Yang et al. ${ }^{4}$, Nian et al. ${ }^{5}$, and Nalbant et al., ${ }^{6}$ applied Taguchi method to optimize cutting parameters in turning process for surface roughness. Asilturk et al., ${ }^{2}$ reported on the use of Taguchi method based response analysis on multi response optimization of $\mathrm{CNC}$ turning. Erzurumlu et al., ${ }^{7}$ made a comparison of Response surface model and Neural Network in determining the surface roughness values on mold surfaces. Zain et al., ${ }^{8}$ applied Genetic Algorithm (GA) and Artificial Neural Network (ANN) as part of artificial intelligent tools in making prediction the best setting of parameters to produces the finest roughness.

Most of the discussion in turning operations is to find the best parameter setting using techniques such as Taguchi method. Additional techniques were also employed such as Neural Network (NN) and Genetic algorithm (GA). However, literatures discusson internal turning (boring) in relation to surface roughness and vibration, are limited. ${ }^{1,4,5}$ Problem frequently encountered in boring is vibration or chatter. In industry, for practical purpose workers put some magnet on boring bar to reduce vibration. Overhang is major problem during boring process, especially if the hole is too long. This can cause the tool to deflect and resulted in detrimental effect on the tool life, surface finish and dimensional accuracy.

This research explores how to damp the vibration produced during internal turning process so that the finish product has better surface roughness. There are three objectives in this research. The first is to demonstrate a systematic procedure of identifying parameter(s) in process control of turning machines. The second is to demonstrate a use of the design of experiment (DoE) in order to identify the optimum setting of parameters to produce best surface roughness. The third is to develop regression model of cutting parameters in internal turning with respect to surface roughness.

\section{Methodology}

\section{Selection of machining parameters}

Based the literature review on machining in turning operations it was found that variables such as feed rate, depth of cut, were identified by previous researcher as parameters that influenced surface roughness. ${ }^{1,4,5}$ Other parameter identified by previous researcher was insert radius. ${ }^{6}$ During machining for internal turning, the problem is that the tool is hanging and when the friction between the tool and the work piece happens it generates the vibrations. The longer the object, the more vibrations would be generated. To overcome this situation many practitioners used a magnet to reduce the vibration. The challenge is to find the right position of dampers such that it will minimize the vibration of the tool. The machining experiments was carried out on Moriseiki NV $2500 \mathrm{CNC}$ lathe, using Tin coated tool with the grade of steel for the machining of AISI 1050 steel bar. Type of material used for this experiment was mild steel (ASSAB 706). The work piece outside diameter was $50 \mathrm{~mm}$, the inside diameter was $30 \mathrm{~mm}$ and the length was $60 \mathrm{~mm}$. Drawing of the work piece is as shown in Figure 1. 


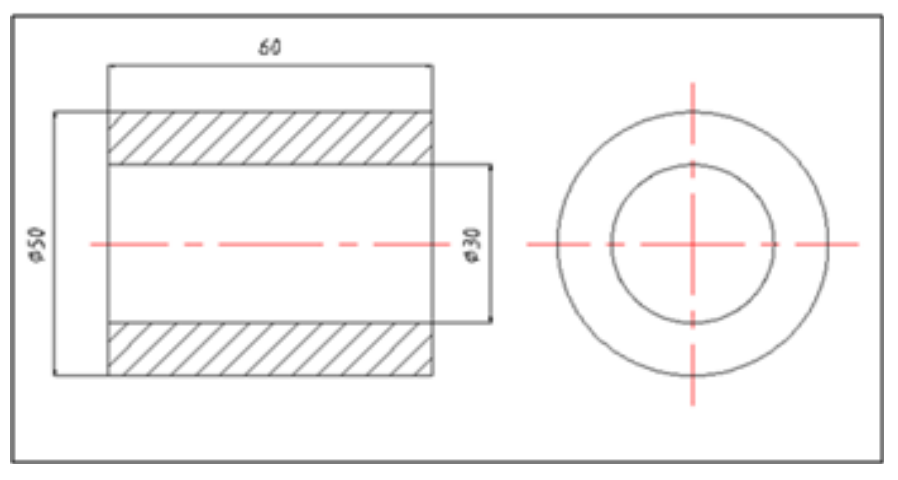

Figure I Dimension of the work piece.

\section{Design of experiment}

There are four machining parameters identified from the literature and best practice to be verified in internal turning, these are: feed rate, depth of cut, insert radius and damper position. Based on previous experiences and literature, each parameter was evaluated at two levels, high and low. By using full factorial design, total of sixteen experiments are needed. For better accuracy three replications were performed for each setting, so in total it there were forty eight experiments. Replication was simply the repeating of experimental runs with the same treatment applied. It was necessary to obtain a valid estimate of experimental error variance. Randomizations of experiments were performed by Minitab software. The sequence of experiment was determined randomly.

\section{Parameters operations}

Table 1 shows the parameters and ranges for this project. These choices are based on the experiences and previous research.

\section{Machining parameters Level}

Table 2 shows the level for each parameter that has been stated above. The parameters were set based on feasible range of cutting parameters and recommended by machining experience.

The damper weight each is 6.4309 gram. The damper is a magnet that put on the holder. The position of dampers was chosen in two positions. The selected position of Damper base on experiences, position 1 parallel to $\mathrm{Y}$ axis of the machine (position on the top of boring bar) and position 2 parallel to $\mathrm{X}$ axis of the machine (position of 3 o'clock of boring bar holder). Figure 2 shows the positions.

Table I General recommendation for turning operation

\begin{tabular}{lllll}
\hline Material & Cutting tool & Depth of cut & Feed, $\mathbf{m m} / \mathbf{r e v}$ & Tool nose radius \\
\hline Mild steel & Carbide & $0.4-12.7$ & $0.1-0.75$ & $0.2 / 0.4$ \\
\hline
\end{tabular}

Table 2 Setting of parameter level

\begin{tabular}{lllll}
\hline Variable level & Damper position & Feed rate & Depth of cut & Insert radius \\
\hline Level I & Position I & $0.1 \mathrm{~mm} / \mathrm{min}$ & $0.25 \mathrm{~mm}$ & $0.2 \mathrm{~mm}$ \\
Level 2 & Position 2 & $0.15 \mathrm{~mm} / \mathrm{min}$ & $0.5 \mathrm{~mm}$ & $0.4 \mathrm{~mm}$ \\
\hline
\end{tabular}

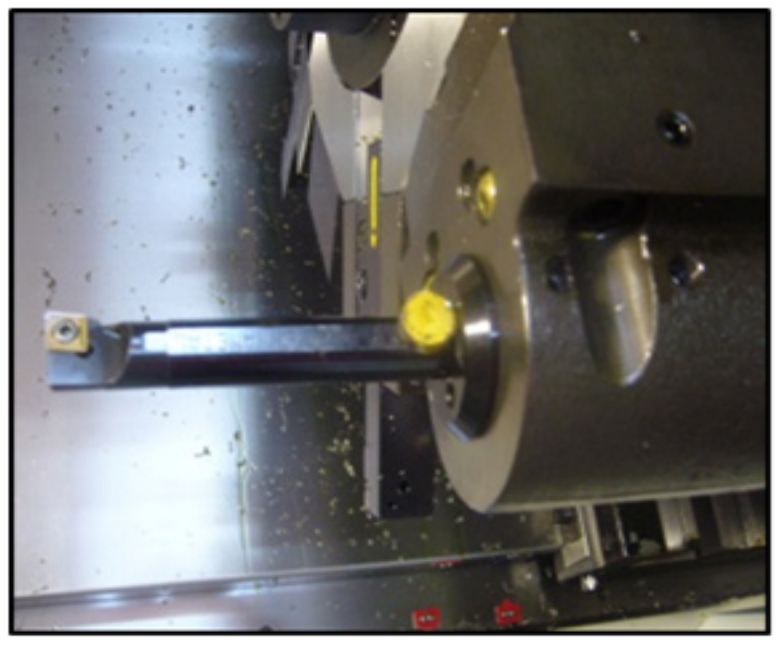

A

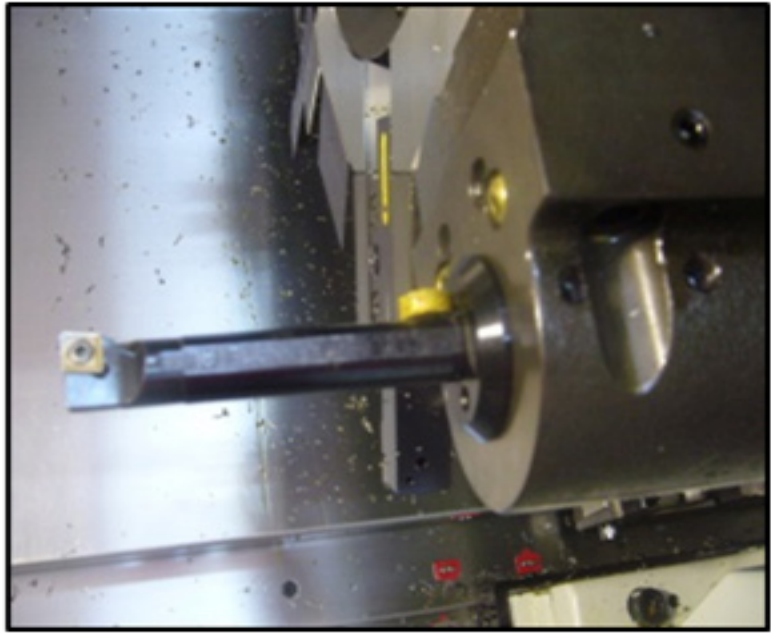

B

Figure 2 Damper positions on the boring bar holder (A) position I and (B) position 2. 


\section{Surface roughness measurement}

The most common instrument used to measure surface finish of product is the profilometer. This device consists of a tracer head and an amplifier. The tracer head houses a diamond stylus, having a point radius of 0.0005 in. $(0.013 \mathrm{~mm})$, which bear against the surface of the work. Any movement of the stylus caused by surface irregularities is converted into electrical fluctuations by the tracer head. These signals are magnified by the amplifier and registered on the meter indicator hand or needle. The reading shown on the meter indicates the average height of surface roughness or the departure of this from the reference line.

\section{Results}

\section{Parameters screening}

Analysis of variance was used to identify which parameters contribute significantly to roughness. The first step all factors and interactions assume to have contribution to the roughness. The data analysis was done using confidence level 90per cent.

Table 3 shows the effect of each factor. Those factors, with $\mathrm{P}$ value larger than 0.10 , are not significant. The effects illustrate the direction of each factor in terms of positive and negative. To improve the analysis, insignificant parameters and interaction of parameters were eliminated. Factors $\mathrm{C}$ and $\mathrm{D}$, are not significant by looking to the $\mathrm{P}$ value larger than 0.10 , however the interaction of $\mathrm{CD}$ and $\mathrm{AD}$ are significant. So factors A damper position and C, depth of cut are maintained in the model representing the effect to roughness.

Table 4 shows the results after screening out insignificant factors. The main effects only factor $\mathrm{D}$ and $\mathrm{B}$ are significant with $\mathrm{P}$ below 0.10 . This also validate the results where two interactions of parameters are happen particularly for $\mathrm{C}$ and $\mathrm{D}$, depth of cut (C) and insert radius (D) interaction and A and D, A (damper position) and D (insert radius) are significant.

Table 3 Estimated effects and coefficients for response (coded units)

\begin{tabular}{llllll}
\hline Term & Effect & Coef & SE Coef & T & P \\
\hline Constant & & 4.0325 & 0.823715 & 4.9 & 0 \\
Damper & -0.6209 & -0.3104 & 0.228458 & -1.36 & 0.184 \\
Feed-rate & -0.4679 & -0.234 & 0.228458 & -1.02 & 0.313 \\
Depth & -0.491 & -0.2455 & 0.228458 & -1.07 & 0.291 \\
Radius & 0.0832 & 0.0416 & 0.228458 & 0.18 & 0.857 \\
Damper*Feed-rate & -0.1417 & -0.0708 & 0.063363 & -1.12 & 0.272 \\
Damper*depth & -0.1839 & -0.0919 & 0.063363 & -1.45 & 0.157 \\
Damper*Radius & -0.1589 & -0.0794 & 0.063363 & -1.25 & 0.219 \\
Feed-rate*depth & -0.2205 & -0.1103 & 0.063363 & -1.74 & 0.091 \\
Feed-rate*Radius & -0.1364 & -0.0682 & 0.063363 & -1.08 & 0.29 \\
depth*Radius & -0.1015 & -0.0507 & 0.063363 & -0.8 & 0.429 \\
Damper*Feed-rate*depth & -0.0614 & -0.0307 & 0.017574 & -1.75 & 0.09 \\
Damper*Feed-rate*Radius & -0.028 & -0.014 & 0.017574 & -0.8 & 0.431 \\
Damper*depth*Radius & -0.049 & -0.0245 & 0.017574 & -1.39 & 0.173 \\
Feed-rate*depth*Radius & -0.0594 & -0.0297 & 0.017574 & -1.69 & 0.101 \\
Damper*Feed-rate*depth*Radius & -0.0165 & -0.0082 & 0.004874 & -1.69 & 0.101 \\
\hline & & & & &
\end{tabular}

Table 4 Analysis of variance after screening parameters

\begin{tabular}{lllllll}
\hline Source & DF & Seq SS & Adj SS & Adj MS & F & P \\
\hline Main Effects & 4 & 12.6097 & 12.6097 & 3.1524 & 12.52 & 0 \\
Damper & $\mathrm{I}$ & 0.0488 & 0.0488 & 0.0488 & 0.19 & 0.662 \\
Feed-rate & $\mathrm{I}$ & 0.856 & 0.856 & 0.856 & 3.4 & 0.073 \\
Depth & $\mathrm{I}$ & 0.1508 & 0.1508 & 0.1508 & 0.6 & 0.444 \\
Radius & $\mathrm{I}$ & 11.5542 & 11.5542 & 11.5542 & 45.87 & 0 \\
2-Way Interactions & 2 & 2.2023 & 2.2023 & 1.1011 & 4.37 & 0.019 \\
\hline
\end{tabular}




\begin{tabular}{lllllll} 
Table Contanued & DF & Seq SS & Adj SS & Adj MS & F & P \\
\hline Source & I & I.II33 & I.II33 & I.II33 & 4.42 & 0.042 \\
Damper*Radius & I & 1.089 & 1.089 & 1.089 & 4.32 & 0.044 \\
depth*Radius & I & 0.8348 & 0.8348 & 0.8348 & 3.31 & 0.076 \\
4-Way Interactions & I & 0.8348 & 0.8348 & 0.8348 & 3.31 & 0.076 \\
Damper*Feed-rate*depth*Radius & 40 & 10.0746 & 10.0746 & 0.2519 & & \\
Residual Error & 4 & 0.7332 & 0.7332 & 0.0916 & 0.31 & 0.955 \\
Lack of Fit & 32 & 9.3414 & 9.3414 & 0.2919 & & \\
Pure Error & 47 & 25.7213 & & & & \\
Total & & & & &
\end{tabular}

\section{Discussion}

Findings from this study are aligned to study by Nalbant et al. ${ }^{1}$, Yang et al. ${ }^{4}$, Nian et al., ${ }^{5}$ on turning study using Taguchi method. They found that surface roughness was strongly correlated to cutting parameters such as insert radius, feed rate, and depth of cut. Further researcher by Sathiskumar ${ }^{9}$ also found that the impact of particle damping during boring operation on roughness. He stated that innovative shatter suppression method based on particle damping technique was found to reduce chatter in boring tool and thereby improve the surface finish. Furthermore, Ramesh et al., ${ }^{10}$ also has done some works on the effect of dampers on roughness in boring operation. He found that improvement of damping capability of boring tool and suppression of chatters can be obtained with four different types of damping materials. The materials having high density produces more inertial mass which is used to suppress the chatter in boring operations. At the end this gives better quality of end product.

The uniqueness of this research is that the damper position was proven to influence the roughness due to, possibly, reduction on tool vibration. It was verified by the experiment that position insert radius level $0.2 \mathrm{~mm}$, the roughness increase when the damper position change from position 1 to position 2. Position 1 is when the damper is put on the top of the holder or in may state as parallel to y-axis, and position 2 when the damper is parallel to $\mathrm{x}$-axis or 90 degrees of $\mathrm{y}$ axis. The results were consistent when the insert radius set to $0.4 \mathrm{~mm}$, the roughness increase when the damper change to position 1 to position 2. So the choice of insert radius and combination of damper position is important to be notice when the experimenter wants to find the reduction on the roughness.

\section{Regression modelling}

Based on the previous discussion it was found that the significant factors are $\mathrm{D}, \mathrm{B}, \mathrm{AD}, \mathrm{CD}$ and $\mathrm{ABCD}$. Table 5 contains information for regression model or sometimes called as mathematical modeling. This model explains the relation or contribution for the factors mentioned above to internal surface roughness (boring) in turning operation.

So the regression model that describes the relationship of dependent variable i.e. surface roughness and the independent variables i.e. Damper position, feed rate, depth of cut and insert radius can be explained as:

$$
\mathrm{X}=4.0373+0.0637(\mathrm{~A})+0.2671(\mathrm{~B})-0.1121(\mathrm{C})+0.9813(\mathrm{D})-
$$
$0.3046(\mathrm{AD})+0.3012(\mathrm{CD})-0.2638(\mathrm{ABCD})$

$\mathrm{X}=$ roughness is a function of $\mathrm{A}=$ Damper position; $\mathrm{B}=$ Feed rate; $\mathrm{C}=$ Depth of cut; $\mathrm{D}=$ Insert radius;

Table 5 Coefficient of parameters after screening for $90 \%$ confidence level

\begin{tabular}{|c|c|c|c|c|c|}
\hline Term & Effect & Coef & SE Coef & $\mathbf{T}$ & $\mathbf{P}$ \\
\hline Constant & & 4.0373 & 0.07244 & 55.73 & 0 \\
\hline A & 0.0637 & 0.0319 & 0.07244 & 0.44 & 0.662 \\
\hline B & 0.2671 & 0.1335 & 0.07244 & 1.84 & 0.073 \\
\hline C & -0.1121 & -0.056 & 0.07244 & -0.77 & 0.444 \\
\hline $\mathrm{D}$ & 0.9813 & 0.4906 & 0.07244 & 6.77 & 0 \\
\hline$A * D$ & -0.3046 & -0.1523 & 0.07244 & -2.1 & 0.042 \\
\hline$C * D$ & 0.3012 & 0.1506 & 0.07244 & 2.08 & 0.044 \\
\hline$A * B * C * D$ & -0.2638 & -0.1319 & 0.07244 & -1.82 & 0.076 \\
\hline \multicolumn{6}{|l|}{$S=0.50|86|$ PRESS $=\mid 4.5074$} \\
\hline$R-S q=60.83 \% R-R-S q($ adj $)=53.98 \%$ & Sq $($ pred $)=$ & $43.60 \%$ & & & \\
\hline
\end{tabular}




\section{Verification of the model}

To verify the model the residual plot is examined. If the residual plot shows abnormalities then the model is not suited, otherwise it indicates that the model is fit represented the relation among the independent variables and dependent variables. The model fits when there exist constant variance assumption does not appear to be violated because the residual are randomly scattered around zero and have approximately the same scattered for all fitted value. Figure 3 shows the residual plot for residual vs. fitted values and residual vs. order of data. The first graph shows an even distribution on zero line it means the variances were even. On the second graph there is no indication that the graph is a function of time. These two indicators confirming that the regression model is fit to the available data.

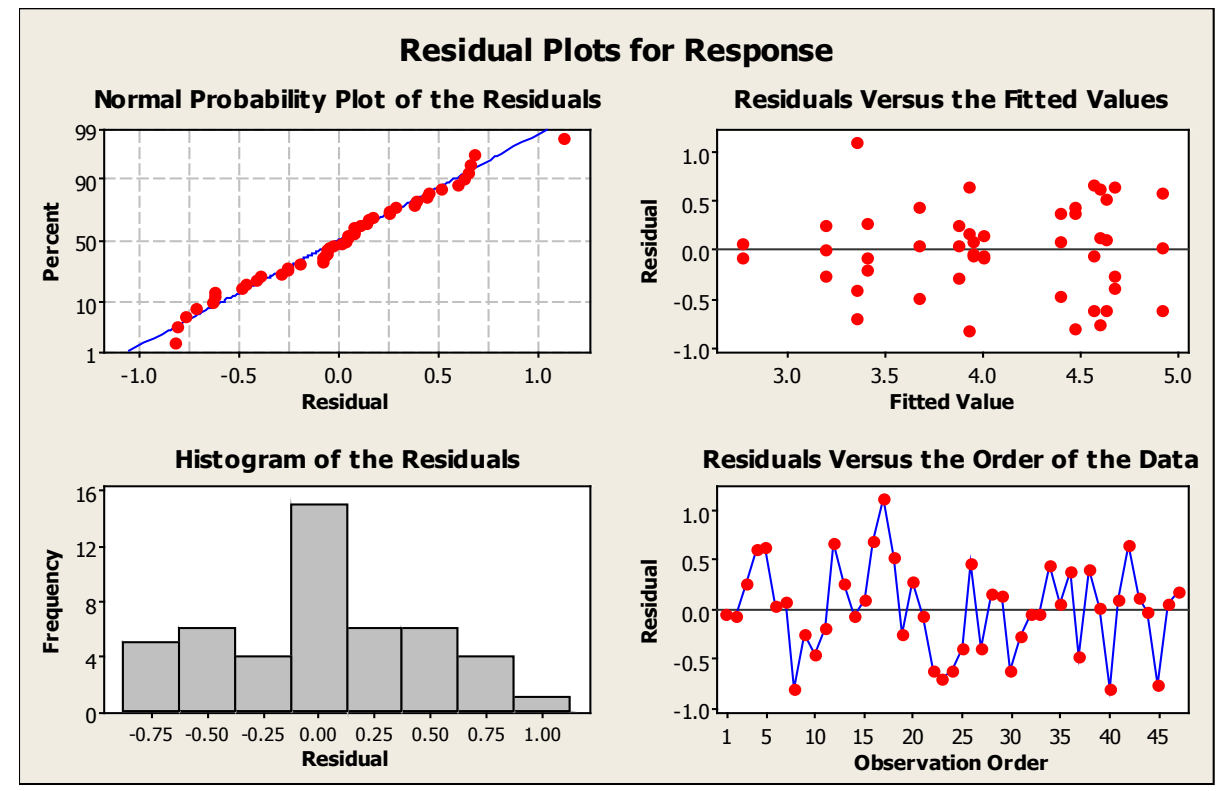

Figure 3 Residual vs Fitted values and Residual vs Observation order.

\section{Validation of model}

To validate the predicted model some data were generated. The experiments were conducted based on the few setting that represent some values. Table 6 shows results of confirmation of three sample experiments and compare with fitted value or predicted value based on the model. It was found the difference between predicted and validation run roughness values were in average 4 percent. This indicates that the model represent the relation between parameters in boring process and the resultant surface roughness.

\section{Optimizing the parameters}

By using Response Optimizer function available in Minitab, it provides the optimum response either minimum or maximum setting of parameters. This function need some input such as significant variables that have been identified before, the result as shown in Figure 4.

Parameters:

$\begin{array}{llllll}\text { Goal } & \text { Lower } & \text { Target } & \text { Upper } & \text { Weight } & \text { Import } \\ \text { E Minimum } 0 & 0 & 4.4 & 1 & 1 & \\ \text { Global Solution } & & & & \\ \mathrm{A}=1 & & & & \\ \mathrm{~B}=1 & & & & \\ \mathrm{C}=2 & & & & \\ \mathrm{D}=1 & \end{array}$

\section{Predicted Responses}

$$
\mathrm{E}=3.15417 \text {, desirability }=0.283144
$$

Composite Desirability $=0.283144$

In Response optimizer the lowest roughness (Ra) given as 3.15417, where the setting given as damper position $(\mathrm{A})=1$; feed rate $(\mathrm{B})=1$; depth of cut $(C)=2$; and insert radius $(D)=1$.

The box plot diagram at Figure 5 illustrates the lowest average of roughness achieved at parameters design for four combination factorial design of damper position $1 *$ feed rate- $1(0.1 \mathrm{~mm} / \mathrm{min}) *$ depth of cut-2 $(0.5 \mathrm{~mm}) *$ insert radius- $1(0.2 \mathrm{~mm})$. This is also confirming as the result of Response Optimizer. ${ }^{11-33}$

\section{Conclusion}

Among the main factors investigated i.e. damper position; feed rate; depth of cut; and insert radius of its effect to roughness, it was found that only feed rate and insert radius are significant factors to roughness in boring process. Among the interaction of two factors and higher, the results showed that two interaction of parameters are not significantly effect to roughness, except for combination of damper position * insert radius and depth of cut *insert radius. For interaction of three factors, none of them are significant. However, for interaction of four parameters i.e. damper position*feed rate* depth of cut* insert radius is significant contribute to the roughness. The study reveals the damper positions do influence the roughness. Optimization of parameters shows that among the setting of parameters and level, the lowest mean of roughness achieved is for combination of damper position 1 (parallel to y-axis) * feed rate $(0.1 \mathrm{~mm} / \mathrm{min}) *$ depth of cut 
$(0.5 \mathrm{~mm}) *$ insert radius $(0.2 \mathrm{~mm})$. The study also performed a regression model for all main factors and their interactions. Verification and validation was performed to confirming the model.

Table 6 Validation of model

\begin{tabular}{lllll}
\hline Term & Coefficient & Sample\#I & Sample\#2 & Sample\#3 \\
\hline Constant & 4.0373 & 4.0373 & 4.0373 & Predict \\
Damper Position & 0.0319 & -0.0319 & -0.0319 & 4.0373 \\
Feed Rate & 0.1335 & -0.1335 & 0.1335 & 0.0319 \\
Depth of Cut & -0.056 & -0.056 & -0.056 & -0.1335 \\
Insert Radius & 0.4906 & -0.4906 & 0.4906 & 0.056 \\
Damper Position * Insert Radius & -0.1523 & -0.1523 & 0.1523 & 0.4906 \\
Depth of cut * Insert radius & 0.1506 & -0.1506 & 0.1506 & -0.1523 \\
Damper Position*Feed rate* & -0.1319 & 0.1319 & 0.1319 & -0.1506 \\
Depth of cut * Insert radius & & & & \\
Predicted result & & 3.15 & 5.01 & 4.05 \\
Experiment result $\mu \mathrm{m}$ & & 2.97 & 5.24 & 3.99 \\
\% Difference & & 6 & 4.5 & 1.5 \\
\hline
\end{tabular}

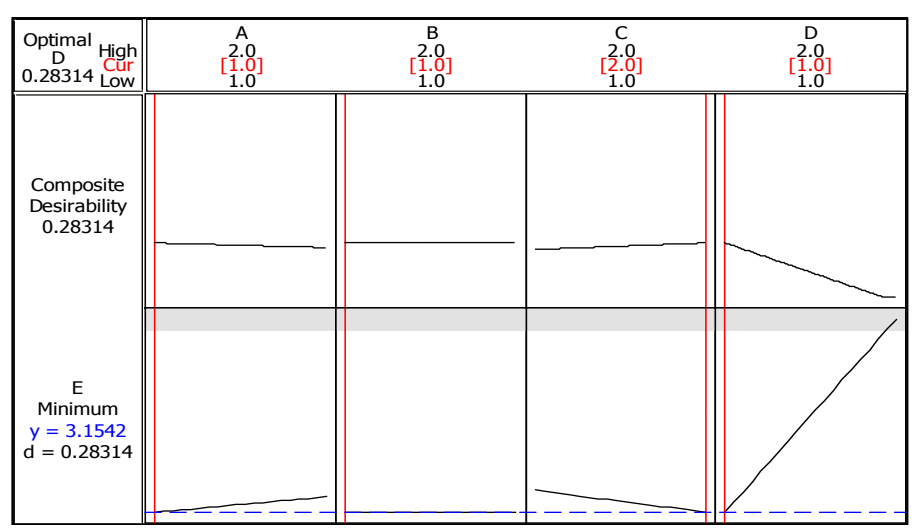

Figure 4 Response optimizer for surface roughness.

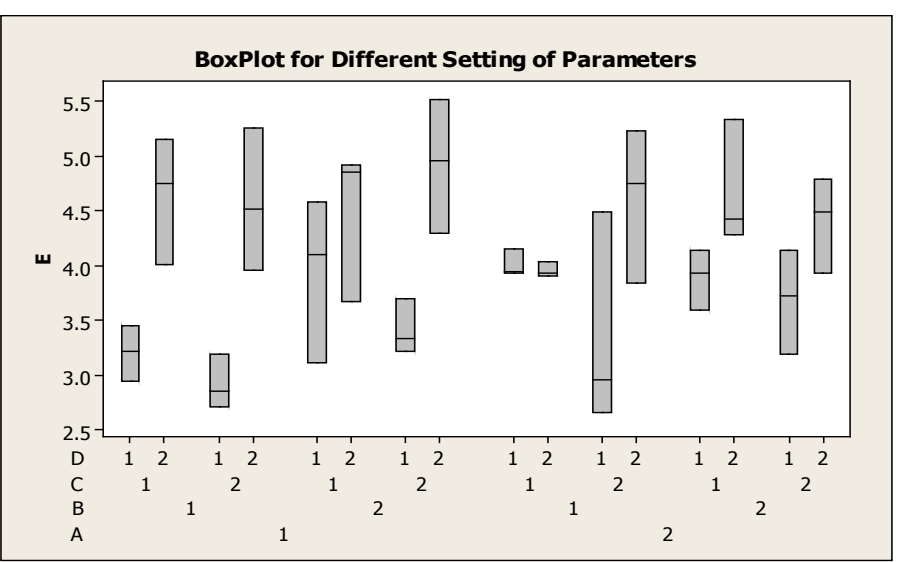

Figure 5 Box plot for internal turing experiments.

Note: E, Roughness;A, Damper position; B, Feed rate; C, Depth of cut; D, Insert radius

\section{Acknowledgments}

The authors extend our sincere thanks to the Universiti Teknikal Malaysia Melaka for continuous support of this research.

\section{Conflicts of interest}

Authors declare that there is no conflict of interest.

\section{References}

1. Nalbant M, Gokkaya H, Toktas I, et al. The experimental investigation of the effects of uncoated, PVD- and CVD- coated cemented carbide insert and cutting parameters on surface roughness in CNC turning and its prediction using artificial neural network. Journal Robotics and Computer-Integrated Manufacturing. 2007;25(1):211-233.

2. Asilturk I, Nazeli S. Multi response optimization of CNC turning parameter via Taguchi method-based response surface analysis. Journal of Measurement. 2012;45(4):785-794.

3. Zain AM, Habibollah H, Sharif S. Prediction of surface roughness in the end milling machining using Artificial Neural Network. Journal Expert System with Application. 2010;37(2):1755-1768.

4. Yang WH, Tang YS. Design optimization of cutting parameters for turning operation based on the Taguchi method. Journal of Materials Processing Technology. 1998;84(1-3):122-129.

5. Nian CY, Yang WH, Tang YS. Optimization of turning operation with multiple performance characteristics. Journal of Material Processing Technology. 1999;95(1-3):90-96.

6. Nalbant M, Gokkaya GS. Application of Taguchi method in the optimization of cutting parameters for surface roughness in turning. Journal Material and design. 2007;28(4):1379-1385.

7. Erzurumlu T, Oktem H. Comparation of response surface model with neural network in determining the surface quality of moulded parts. Journal of Material \& Design. 2007;28(2):459-465.

8. Zain AM, Habibollah H, Sharif S. Application of GA to optimize 
cutting conditions for minimizing surface roughness in the end milling machine process. Journal Expert System with Application. 2010;37(6):4650-4659.

9. Sathishkumar B. Experimental Studies on Impact of Particle Damping on Surface Roughness of Machined Components in Boring Operation. Europe Journal of Scientific Research. 2012;71(3):327-190.

10. Ramesh K. Investigation of Modal Analysis in the Stability of Boring Tool using Double Impact Dampers Model Development. Europe Journal of Scientific Research. 2012;80(2):182-190.

11. Axinte DA, Belluco W, Chiffre LD. Reliable Tool Life Measurement In Turning - an application to cutting fluid efficiency evaluation. International Journal of Machine Tools \& Manufacture. 2000;41(7):1003-1014.

12. Aggrawal A, Singh H. Optimization of machining techniques-A retrospective and literature review. Dept of mechanical and Automation Engineering, Maharaja Agrasen Institute of Technology, India; 2005.

13. Abeesh BC, Dabade UA, Joshi SS, et al. Modeling of surface roughness in precision machining of metal matrix composites using ANN. Journal of Material Processing Technology. 2008;197(1-3):439-444.

14. Al-Ahmari AM A. Predictive machinability models for a selected hard material in turning operations. Journal of Material Processing Technology. 2007;190:305-311.

15. Benardos PG, Vosnaikos GC. Predicting surface roughness in machining: a review. International Journal of Machine Tools and Manufacturing. 2003;43(8):833-844.

16. Boothroyd G, Knight WA. Fundamentals of machining and Machine Tools. Marcel Dekker, 2nd edition; 1989.

17. Ezugwu EO, Fadare DA, Bonneya J, et al. Modelling the correlation between cutting and process parameters in high-speed machining of Inconel 718 alloy using an artificial neural network. International Journal of Machining Tools and Manufacturing. 2005;45(1213):1375-1385.

18. Isakov E. Understanding Boring Bar Deflection. MMS Online articles; 2000 .

19. Jawaid A, Koksal S, Sharif S. Cutting performance and wear characteristic of PVD coated and uncoated carbide tool in face milling of Inconel 718. Journal of Material Processing Technology. 2001;116(1):2-9.

20. Karayel D. Prediction and Control of surface roughness in CNC lathe using artificial neural network. International Journal of materials processing technology. 2009;209(7):3125-3137.
21. Kalpakjian S, Schmid S. Manufacturing Engineering Technology. 6th edition in SI units. Person Education South Asia Pte. Ltd; 2010.

22. Kneisel T, Schulz H. Turn-Milling of Hardened Steel-an Alternative to Turning. Journal Manufacturing Technology. 1994;43(1):93-96.

23. Lou MS, Chen JC, Li CM. Surface Roughness Prediction Technique for CNC. Journal of Industrial Technology. 1998;15(1).

24. Montgomery DC. Design and Analysis of Experiment. 8th ed. Wiley: New York; 2012.

25. Martinez LV, Carlos J, Eduardo R, et al. Analysis of Compliance between the cutting tool and the work piece on the stability of a turning process. Journal of Machining Tools \& Manufacturing. 2008;48(9):1054-1062.

26. Nazeli S, Yaldiz S, Turkes E. Optimization of tool geometry parameter for turning operations based on the response surface methodology. Journal of Measurement. 2010;44(3):580-587.

27. Nian CY, Yang WH, Tang YS. Optimization of turning with multiple performance characteristics. Journal of Material Processing Technology. 1998;95(1-3):90-96.

28. Quesada R. Computer numerical Controller machining ad Turning Centre. Pearson Education, Inc: Upper Saddle River, New Jersey; 2005.

29. Saravanan R, Asokan P, Sachithanandam M. Comparative Analysis of Conventional and Non-Conventional Optimizations Techniques for CNC Turning Process. Journal of Advance Manufacturing Technology. 2001;17:471-476.

30. Son SM, Lima HS, Ahn JH. The effect of vibration cutting on minimum cutting thickness. International Journal of Machine Tool \& Manufacturing. 2006;46(15):2066-2072.

31. Valentino JV, Goldenberg J. Introduction to Computer Numerical Controller (CNC). 4th ed. Pearson Education Inc: New Jersey; 2008.

32. Wang X, Da ZJ, Jawahir IS, et al. Performance based Predictive Model and Optimization method for Operations and applications: part 3Optimum Cutting Conditions and selection of Cutting Tools. Journal of manufacturing Process. 2007;9(1):61-74.

33. Zhou C, Richard A. An integrated system for selecting optimum cutting speeds and tool replacement times. Journal of Machine Tools and Manufacture. 1992;32(5):695-707. 